\title{
Retrospective assessment of solvent exposure in paint manufacturing
}

\author{
Deborah C Glass, Anne Spurgeon, Ian A Calvert, John L Clark, J Malcolm Harrington
}

\begin{abstract}
This paper describes how exposure to solvents at two large paint making sites was assessed in a study carried out to investigate the possibility of neuropsychological effects resulting from long term exposure to organic solvents. A job exposure matrix was constructed by buildings and year. A detailed plant history was taken and this was used to identify uniform exposure periods during which workers' exposure to solvents was not thought to have changed significantly. Exposure monitoring data, collected by the company before the study, was then used to characterise exposure within each uniform exposure period. Estimates were made for periods during which no air monitoring was available. Individual detailed job histories were collected for subjects and controls. The job histories were used to estimate exposure on an individual basis with the job exposure matrix. Exposure was expressed as duration, cumulative dose, and intensity of exposure. Classification of exposure by duration alone was found to result in misclassification of subjects.
\end{abstract}

(Occup Environ Med 1994;51:617-625)

Keywords: exposure assessment, solvent, occupational hygiene monitoring, job exposure matrix

Over the last 20 years claims have been made, particularly in Nordic countries, that long term occupational exposure to organic solvents can produce permanent adverse effects on the central nervous system..$^{1-3}$ It is of particular interest to know whether exposures at or below current exposure limits result in these types of effects. In many studies, comparisons were made between the neuropsychological performance of populations assumed to be either exposed or non-exposed. This does not greatly help in the assessment of possible dose-effect relations except in terms of duration of exposure. ${ }^{14}$ The extent of exposure has been quantified in relatively few studies, ${ }^{5-9}$ hence a study at a plant where exposure data is available is of interest. In our study occupational hygiene monitoring carried out over 15 years in two paint making plants (A and B) showed that exposure had been typically below the current United Kingdom occupational exposure limits
(OELs). These data formed the basis of the individual exposure assessments used in an investigation of the potential neuropsychological effect of exposure to low levels of organic solvents. The performance in neuropsychological tests of workers exposed to solvents from the paint making facilities, plants $\mathrm{A}$ and $B$, was compared with that of non-exposed controls from a fibre making factory, plant C. The results of that investigation are reported elsewhere. ${ }^{10}$

This paper describes the process by which the exposure to solvents was assessed on an individual basis and how the population was then subdivided into groups for the analysis of any effect.

The objectives of the exposure assessment were twofold: (a) to ensure that the subjects had been exposed to solvents and that the controls from plant $\mathrm{C}$ had not been occupationally exposed to solvents, that is, were a suitable control group; $(b)$ to divide the subjects on the basis of their exposure into reasonably defensibly homogeneous groups to analyse for any dose-effect relation that may exist. It was important that the group should be well characterised as it is well known that non-differential misclassification of subjects reduces the sensitivity of a study. ${ }^{1112}$

\section{Subjects and methods}

METHOD OF ASSESSMENT OF EXPOSURE

Exposure was assessed in three ways. The simplest method was to use duration of exposure alone. The second method was to calculate personal dose of solvent accumulated by each subject with exposure monitoring data from the company. The expected exposure was estimated from the monitoring data by considering exposure to be cumulative, after the model developed by Dement et al. ${ }^{13}$ The mean time weighted average air concentration was estimated for each year of exposure and the estimates summed. The third method was to calculate intensity of exposure from the cumulative data divided by the duration expressed as the number of years of exposure. This is the lifetime weighted average exposure used by Ford et al. ${ }^{8}$

Assessment of exposure therefore consisted of five elements: (a) collection of the personal job histories; $(b)$ assessment of plant histories; (c) preparation of a job exposure matrix for plants A and B; (d) personal job exposure assessment; (e) formation of homogeneous groups. 
Collection of the personal job histories

(1) Fob history questionnaire-Each participant completed a job history questionnaire that was based on one used in a previous survey of the neuropsychological effects of occupational exposure to solvents. ${ }^{14}$ Subjects and controls were asked to give their job title and to identify the site and building in which they worked by its number and to indicate how many years and months they had been employed in that job. They were then asked to identify other jobs that they had held at the plant, by job title and building and to give the number of years for which they had been employed in that job, and the year that the job started.

Subjects and controls were also asked to identify and to describe hobbies and jobs outside plants $A, B$, and $C$ that were held for more than three months that involved the use of solvents, and then to provide information on the materials handled in relation to the method of exposure, length of exposure/day and number of days/month that each was used.

(2) Exposure and non-exposure criteria-The definition of exposure required for inclusion as a subject and non-exposure criteria for the controls were defined first. For inclusion as a subject a person had to have held a job or jobs exposed to solvents for a minimum total period of three years. There are jobs inside the paint making facilities where exposure is not considered to be significant, and the time spent in these jobs was not included in the assessment. A job exposed to solvents was also defined first. When the job histories were completed each of them was examined by the company's group hygienist and separately by the particular plant hygienist, who used the criterion "was the subject's job likely to expose him to any more solvent than the rest of the general population outside plants $A$ and B". For example, work in a warehouse with only closed tins of paint was considered to be non-exposed. Previous jobs outside the company, held for $\geqslant 6$ months where there was at least $16 \mathrm{~h} / \mathrm{month}$ exposure to solvents were considered to constitute significant exposure, and were included in the calculation of the years of exposure. Solvent exposure resulting from hobbies was not included in the years of exposure.

Controls from plant $\mathrm{C}$ were considered to be exposed if they had a job or hobby that involved handling solvent for $>16 \mathrm{~h} / \mathrm{month}$ for $\geqslant 3 y$. These controls were then excluded from the study. A small group of workers in plant C was involved in the cleaning of nylon extruder heads with solvents. This group was excluded from the study.

(3) Years of exposure-Years of exposure are the total number of years spent in jobs exposed to solvents inside and outside the paint making plants. This figure was termed duration of exposure.

\section{Assessment of plant histories}

The plant hygienists were interviewed and histories of the main solvent handling areas of plants A and B were assembled. These were sent to the plant hygienists for verification and correction where necessary. The interview was structured to try to ensure consistency and completeness. A list of factors likely to affect exposure was drawn up in advance of the interview and the history of, and changes pertaining to each building and area were discussed in relation to the list. The factors were as follows.

(1) Fob organisation - An understanding of the way in which different tasks related to job title and how this might have changed over time was thought to be potentially important.

(2) Work practices-The types of activity carried out within a task and the equipment used was considered.

(3) Solvents used-Different areas used different combinations of solvents and there were changes in these over time.

(4) Production level-Significant changes in production or the amount of overtime worked could affect exposure.

(5) Cleaning procedure-It was known that in the past, cleaning procedures included the use of large amounts of solvent. This practice has changed.

(6) Ventilation-There have been changes in local and general ventilation over the period in question and this has reduced exposure.

(7) Personal protective equipment-This may reduce exposure if the equipment is of the appropriate type. Exposure measurements are usually taken outside the equipment.

Preparation of a job exposure matrix for plants $A$ and $B$

(1) Plant solvent monitoring programmeSince about 1979, an occupational hygiene monitoring programme for solvents has been carried out at plants A and B. Pumped charcoal tubes were used until 1982 with analysis by gas chromatography or flame ionisation detector carried out for both plants, at plant A. In 1982 passive sampling was introduced with an ATD50 GC analyser also based at plant A.

Since 1985 the results of hygiene sampling have been computerised. The data from 1980 have recently been computerised. Exposure data were obtained from the company in computer readable form and manipulated with Dbase IV and the Statistical Packages for the Social Sciences (SPSS). ${ }^{15}$ Data pertaining to earlier years and for 1981 to 1984 inclusive were retrieved from paper records.

The original air monitoring data were collected to establish compliance with published United Kingdom OELs, so sampling and analysis were carried out for individual solvents. The concentrations (ppm) were compared with the relevant exposure limits. As several solvents may be present that have similar effects the "mixtures formula" developed by $\mathrm{ACGIH}^{16}$ was also used by the company to establish compliance.

(2) Fob exposure matrix construction-A spreadsheet was prepared for each site that cross tabulated building and year. The cells contained a code to indicate important 
Table 1 Exposure data calculated as a mixture-1980 and 1985-1990

\begin{tabular}{|c|c|c|c|}
\hline \multirow[b]{2}{*}{ Building (site) } & \multirow[b]{2}{*}{$\begin{array}{l}\text { Observations } \\
(n)\end{array}$} & Mixtures calculations & \multirow[b]{2}{*}{$\%>1$} \\
\hline & & $\begin{array}{l}\text { Arithmetic } \\
\text { mean (range) }\end{array}$ & \\
\hline Fillin & 27 & 0.06 & 0 \\
\hline lis (A) & 49 & $0.13(0.02-0.97)$ & 0 \\
\hline Mocoil (A) & 302 & $0.19(0.02-4.64)$ & $1 \cdot 0$ \\
\hline Labs (A) & 17 & $0.36(0.01-5.15)$ & $5 \cdot 9$ \\
\hline Decorative (A) & 19 & $0.04(0.00-0.11)$ & 0 \\
\hline Decant (A) & 9 & $0.08(0.00-0.22)$ & 0 \\
\hline Resi & 74 & $0.05(0.01-0.57)$ & 0 \\
\hline Engineering (B) & 68 & $0.07(0.01-0.64)$ & 0 \\
\hline Labs (B) & 249 & $0.19(0.01-4.56)$ & $2 \cdot 0$ \\
\hline Solvent farm (B) & 18 & $0.47(0.01-6.00)$ & $11 \cdot 1$ \\
\hline $\mathrm{CMB}^{\star}(\mathrm{B})$ & 723 & $0.32(0.00-12.84)$ & $4 \cdot 2$ \\
\hline Filling (B) & 139 & $0.16(0.00-1.07)$ & $0 \cdot 7$ \\
\hline Big batch plant ${ }^{\star}(B)$ & 49 & $0.1(0.00-0.63)$ & 0 \\
\hline laim (B) & 18 & $0.5(0.04-5.98)$ & $5 \cdot 6$ \\
\hline Resin & 206 & $0.3(0.00-5 \cdot 61)$ & 1.5 \\
\hline
\end{tabular}

*Where more than one building is involved, mean of means was taken.

changes in the plant or processes that would affect exposure, for example changes in cleaning procedures or in local and general ventilation. As the main factors affecting the extent of exposure had not changed, the period between such changes can be expected to have a uniform exposure and this period was identified as a uniform exposure period (UEP). Air monitoring data taken over periods longer than 180 minutes were identified for plants A and B. For each air sample the total concentration of solvent in the air was expressed as the sum of the ppm of all the individual solvent components. For each building, an arithmetic mean was taken of all monitoring data that had been taken within a UEP. This figure was used to represent the average exposure in that building, for that job, during that period. Different amounts of data were available for each UEP so two sided Mann Whitney tests were used to determine whether the distributions of data within consecutive UEPs were significantly different from one another.

(3) Retrospective exposure assessments without monitoring results-Where data did not exist within a UEP, the plant hygienist was asked to estimate the likely exposure. He was given data for other UEPs, for that area, reminded of the changes in exposure factors that had taken place and asked to estimate in percentage terms the likely exposure changes that had taken place.

(4) Compliance matrix-Data were drawn from the computerised records (1980, and 1985-1990) and the mixtures formula was recalculated with common denominators, based on the 1992 United Kingdom exposure limits $^{17}$ (table 1).

\section{Personal job exposure assessment}

A time sheet was drawn up for all subjects for whom an adequate job history had been obtained $(n=104)$. This showed the years of work at the paint making facility and the building and area associated with each year. The time weighted average (TWA) total exposure for solvents (ppm) was drawn from the matrix with the value from the appropriate UEP. Where subjects worked in more than one area the percentage time in each area, given by the subject, was used to calculate exposure. Personal dose estimates were then drawn up with the model described by Dement et al..$^{13}$

$$
E(T)=\sum_{i=1}^{N} C_{i} t_{i}
$$

where: $E=$ cumulative exposure estimate; $T$ = duration of employment; $\mathrm{C}_{\mathrm{i}}=$ solvent concentration for job $\mathrm{i}$ during calendar time period that worker was employed in that job; $\mathrm{t}_{\mathrm{i}}=$ time spent in job $\mathrm{i} ; \mathrm{N}=$ number of jobs held until time $\mathrm{T}$.

For a few subjects, an estimation was made of exposure to solvents experienced during jobs outside the paintmaking facilities or from paint making jobs that had not been monitored or for which there were no monitoring data available. Data from similar exposures within the plants were used as the estimates of exposure in these cases.

\section{Forming homogeneous groups}

The data gathered from the exposure assessment were used to divide the exposed population into high, medium, and low exposure groups for each of the three assessment methods. As far as possible natural divisions in the distribution of the subjects were used to generate groups of about equal size.

\section{Results}

JOB HISTORIES

Job histories were analysed for jobs that resulted in exposure to solvents. One hundred and ten workers were found to have had $>3$ years of exposure. Complete data on job title and building was available for 104 of these workers. About $40 \%$ of paintmakers who completed questionnaires, were excluded, mainly on the basis that they had not had $>3$ years work in an exposed job or had certain medical conditions. ${ }^{10}$ There were eight subjects with hobbies that might have exposed them to significant levels of solvent, and 19 who had jobs other than paint making where exposure to solvents might have been signifi- 
cant. Figure 1 shows a histogram of the years of exposure.

About $34 \%$ of potential controls were excluded mainly because they were surplus to requirements having been selected as controls for paintmakers who were subsequently excluded. A further 10 potential controls were excluded on the basis that they had had $>3$ years of exposure to solvents in jobs outside the company. No controls reported hobbies involving significant solvent exposure $(>16$ $\mathrm{h} /$ month) although the question was left blank by two controls. Five controls had worked with solvents for between 3 months and 3 years.

\section{PLANT HISTORIES}

Detailed plant histories were taken for each area and the main findings are summarised below.

(1) Job organisation has changed little at plant B over the past 30 years. At plant A, workers used to have well defined jobs but job flexibility was introduced in 1976 and extended until by 1982 new workers were required to be entirely transferable within a building. In all cases an $8 \mathrm{~h}$ shift is the norm.

(2) Work practices have not changed significantly in most areas although there has been a decline in use of portable bins to transport solvent and paint. Solvents were more likely to be transported in pipelines since the 1960s. A new facility was constructed in 1976 at plant $\mathrm{A}$, for the manufacture of decorative paint. This resulted in more specialist production of industrial paints in the older area. At this time there were changes in various items of plant such as those used for mixing the paint.

(3) Table 2 shows the solvents used at plants $\mathrm{A}$ and $\mathrm{B}$. These have changed little. There have been a few changes in some specific areas, for example, glycol ethers have largely been phased out. Organic solvents were eliminated from one building in 1988 . Little white spirit has been used in several areas since 1976 after production transferred to the new facility.

(4) Production levels and overtime have fluctuated but were not considered to have changed systematically over the period and were not included in the analysis.

(5) Cleaning procedures have not changed a great deal in plant $B$. In plant $A$ there was a regular clean down of production areas including floors, on Saturday mornings with white spirit or recovered solvent. This practice led to high exposures and was stopped in

Table 2 Solvents used in paintmaking

\begin{tabular}{ll}
\hline Compound & $\begin{array}{c}\text { Current United Kingdom OEL (ppm) } \\
(8 \mathrm{~h} \text { TWA unless otherwise specified) }\end{array}$ \\
\hline Acetone & 750 \\
Isobutyl alcohol & 50 \\
Methyl ethyl ketone & 200 \\
Methyl isobutyl ketone & 50 \\
N-butyl acetone & 150 \\
N-butyl alcohol & 50 (STEL) \\
Toluene & 50 \\
White spirit & 100 \\
Xylene & 100 \\
\hline STEL = short term exposure limit.
\end{tabular}

1982. Only areas of $<1 \mathrm{~m}^{2}$ can now be cleaned with waste solvent and general floor cleaning is prohibited.

(6) Local exhaust ventilation has been changed in several areas of plants A and B. Not all the changes have led to significant reductions in solvent exposure according to the monitoring data that were available.

(7) There have been few significant changes to the personal protective equipment available. Air fed suits were installed in 1975 in one area. No other respiratory protective equipment is used on a daily basis.

\section{EXPOSURE MATRICES}

(1) Matrices used for exposure assessment

Table 3 and 4 are the exposure matrices created for plant $A$ and $B$, and present the arithmetic mean of the total ppm of organic solvent, within each UEP. These matrices were used to calculate cumulative exposure and intensity of exposure for individual subjects. The jobs outside the company were mostly in engineering or as a fitter $(n=12)$ and the exposure of $9 \mathrm{ppm}$ was used as the typical solvent exposure. This figure was drawn from the value for the engineering group, an equivalent job area in plant B. For the printer employed outside plant $A(n=1)$ the figure for printing inside plant $A$ of 20 ppm was used. For painting and decorating outside the company $(n=4)$ and the dehydration area, where exposures were considered by the plant hygienists to be high but measurements were not available a figure of $120 \mathrm{ppm}$ was used, the highest level measured in the study.

\section{(2) Compliance matrix}

Table 1 shows the results of the analysis by compliance. These data are included to allow comparison with current exposure limits. A value $>1$ indicates non-complaint exposure with United Kingdom 1992 OELs.

\section{FORMATION OF EXPOSURE GROUPS \\ (1) Duration of exposure}

Exposed subjects $(n=110)$ were divided into four groups on the basis of duration of exposure (y). This gave the following groups; $<11$ y $(\mathrm{n}=39), 11-20 \mathrm{y}(\mathrm{n}=43), 21-30 \mathrm{y}(\mathrm{n}=17)$, and $>30$ y $(\mathrm{n}=11)$.

\section{(2) Cumulative exposure}

The cumulative exposures represent the sum of mean daily concentration ( $8 \mathrm{~h}$ TWA) to solvents measured in ppm multiplied by years of exposure. The exposures ranged from 12 ppm.y to 1800 ppm.y. Exposed subjects for whom adequate data were available, were divided into three groups of about equal size. These were those subjects with $<300 \mathrm{ppm}$.y $(n=42), \quad 300-600$ ppm.y $(n=37)$, and $>600$ ppm.y $(n=25)$. There was only one person between 580 and 700 ppm.y and so there was a natural division at this point.

(3) Intensity of exposure

Intensity of exposure was calculated for the 104 subjects for whom adequate data were 
Table 3 Plant $A$ exposure matrix

\begin{tabular}{|c|c|c|c|c|c|c|c|c|c|c|c|c|c|}
\hline \multirow[b]{2}{*}{ Year } & \multicolumn{13}{|c|}{ Building No } \\
\hline & 15 & 17 & 24 & 29 & 63 & 117 & 121 & 146 & 180 & 190 & 192 & 201 & 209 \\
\hline 1990 & $15 \cdot 3$ & $12 \cdot 3$ & 8 & 3.6 & 0.5 & 16 & $46 \cdot 6$ & 0 & $7 \cdot 4$ & $4 \cdot 5$ & 6 & $1 \cdot 1$ & 1.7 \\
\hline 1989 & $15 \cdot 3$ & 12.3 & 8 & 3.6 & 0.5 & 16 & $46 \cdot 6$ & 0 & $7 \cdot 4$ & & 6 & $1 \cdot 1$ & 1.7 \\
\hline 1988 & 15.3 & 12.3 & 8 & 3.6 & 0.5 & 16 & 46.6 & $\mathrm{~s} 5 \cdot 7$ & $7 \cdot 4$ & 4.5 & 6 & $1 \cdot 1$ & 1.7 \\
\hline $\begin{array}{l}1900 \\
1987\end{array}$ & 15.3 & 12.3 & 8 & 3.6 & 0.5 & $\begin{array}{l}10 \\
\text { v18.4 }\end{array}$ & $\begin{array}{l}\begin{array}{l}400.0 \\
46.6\end{array} \\
\end{array}$ & 5.7 & $7 \cdot 4$ & 4.5 & $\begin{array}{l}0 \\
6\end{array}$ & 1.1 & $\begin{array}{l}1.7 \\
1.7\end{array}$ \\
\hline $\begin{array}{l}1986 \\
1986\end{array}$ & 15.3 & 12.3 & $\stackrel{\circ}{\mathrm{p} 14^{-}} \mathbf{4}^{\star}$ & $\begin{array}{r}5.0 \\
\text { v5.4 }\end{array}$ & $\begin{array}{r}\text { v2.9 } \\
\text {. }\end{array}$ & $\begin{array}{r}18.4 \\
18.4\end{array}$ & $\begin{array}{c}40.0 \\
\text { v10.6 }\end{array}$ & 5.7 & $7 \cdot 4$ & 4.5 & $\begin{array}{l}0 \\
6\end{array}$ & 1.1 & $\begin{array}{l}1.7 \\
1.7\end{array}$ \\
\hline $\begin{array}{l}1980 \\
1985\end{array}$ & $\begin{array}{l}15.3 \\
15.3\end{array}$ & ev9.5 & $\begin{array}{c}\mathrm{p} 14.4 . \\
14.4\end{array}$ & $\begin{array}{r}\quad 5.4 \\
5.4\end{array}$ & $\begin{array}{r}8.9 \\
2.9\end{array}$ & $\begin{array}{l}18.4 \\
18.4\end{array}$ & $\begin{array}{l}10 \cdot 6 \\
10 \cdot 6\end{array}$ & 5.7 & 7.4 & $\begin{array}{l}4.5 \\
4.5\end{array}$ & $\begin{array}{l}0 \\
6\end{array}$ & $\begin{array}{l}1.1 \\
1.1\end{array}$ & $\begin{array}{l}1.1 \\
1.7\end{array}$ \\
\hline 1984 & $15 \cdot 3$ & $9 \cdot 5$ & $14 \cdot 4$ & 5.4 & 2.9 & 18.4 & 10.6 & $5 \cdot 7$ & $7 \cdot 4$ & 4.5 & 6 & $1 \cdot 1$ & 1.7 \\
\hline 1983 & 15.3 & $9 \cdot 5$ & 14.4 & 5.4 & 2.9 & 18.4 & 10.6 & $5 \cdot 7$ & $7 \cdot 4$ & 4.5 & 6 & $1 \cdot 1$ & 1.7 \\
\hline 1982 & 15.3 & $\mathrm{cl} 2 \cdot 3$ & $\begin{array}{l}14.4 \\
\end{array}$ & 5.4 & 2.9 & $\mathrm{c} 27.6^{\star}$ & 10.6 & $5 \cdot 7$ & $7 \cdot 4$ & $4 \cdot 5$ & 6 & $1 \cdot 1$ & $c 7 \cdot 6^{\star}$ \\
\hline 1981 & 15.3 & 12.3 & 14.4 & 5.4 & 2.9 & $27 \cdot 6$ & 10.6 & 5.7 & $7 \cdot 4$ & 4.5 & 6 & $1 \cdot 1$ & 7.6 \\
\hline 1980 & 15.3 & 12.3 & 14.4 & $5 \cdot 4$ & 2.9 & $27 \cdot 6$ & 10.6 & 5.7 & $7 \cdot 4$ & 4.5 & 6 & $1 \cdot 1$ & 7.6 \\
\hline 1979 & 15.3 & $12 \cdot 3$ & $\mathrm{p} 33.8^{\star}$ & $5 \cdot 4$ & 2.9 & $27 \cdot 6$ & 10 & 5.7 & $7 \cdot 4$ & 4.5 & 6 & $1 \cdot 1$ & v9.4* \\
\hline 1978 & $15 \cdot 3$ & $12 \cdot 3$ & 33.8 & $5 \cdot 4$ & 2.9 & $27 \cdot 6$ & 10 & $5 \cdot 7$ & $7 \cdot 4$ & 4 & 6 & $1 \cdot 1$ & $9 \cdot 4$ \\
\hline $\begin{array}{l}1977 \\
1977\end{array}$ & $15 \cdot 3$ & $\mathrm{~s} 12.3$ & 33.8 & $5 \cdot 4$ & 2.9 & e30 & 10 & $5 \cdot 7$ & $7 \cdot 4$ & 4.5 & 6 & $1 \cdot 1$ & $9 \cdot 4$ \\
\hline 1976 & e30 & $12 \cdot 3$ & & $5 \cdot 4$ & 2.9 & ejp30 & 10.6 & $5 \cdot 7$ & $7 \cdot 4$ & v4.5 & 6 & $1 \cdot 1$ & $9 \cdot 4$ \\
\hline 1975 & 30 & j $12 \cdot 3$ & & $5 \cdot 4$ & 2.9 & e 30 & e10.6 & 5.7 & $7 \cdot 4$ & 4. & 6 & $1 \cdot 1$ & built \\
\hline 1974 & 30 & v15 & 33.8 & 5.4 & 2.9 & e 30 & 10.6 & $5 \cdot 7$ & $7 \cdot 4$ & 4 & 6 & $1 \cdot 1$ & - \\
\hline 1973 & 30 & 15 & 33.8 & 5.4 & 2.9 & 30 & 10.6 & 5.7 & $7 \cdot 4$ & 4. & 6 & $1 \cdot 1$ & - \\
\hline 1972 & 30 & 15 & 33.8 & $5 \cdot 4$ & 2.9 & 30 & 10.6 & $5 \cdot 7$ & $7 \cdot 4$ & 4. & 6 & $1 \cdot 1$ & - \\
\hline 1971 & 30 & 15 & 33.8 & $5 \cdot 4$ & 2.9 & 30 & 10.6 & $5 \cdot 7$ & $7 \cdot 4$ & 4.5 & 6 & $1 \cdot 1$ & - \\
\hline $\begin{array}{l}1970 \\
\end{array}$ & 30 & 15 & 33.8 & 5.4 & 2.9 & 30 & 10.6 & 5.7 & 7.4 & 4.5 & 6 & $1 \cdot 1$ & $\overline{-}$ \\
\hline 1969 & 30 & 15 & 33.8 & 5.4 & 2.9 & 30 & 10.6 & 5. & $7 \cdot 4$ & 4. & 6 & $1 \cdot 1$ & $\overline{-}$ \\
\hline 1968 & 30 & 15 & 33.8 & 5.4 & 2.9 & 30 & 10.6 & 5.7 & $7 \cdot 4$ & 4.5 & 6 & 1.1 & - \\
\hline
\end{tabular}

${ }^{*} \mathrm{P}<0.05 \mathrm{Mann}$-Whitney two tailed test. Hygienist estimated UEPs in italics. Type of change- $v=$ ventilation; $p=p l a n t$ $c=$ cleaning; $j=$ job definition; $\mathrm{e}=$ enclosure; $\mathrm{s}=$ change in solvents; ppe = personal protective equipment.

available. The yearly mean intensity exposures ranged from $2 \cdot 6-60 \mathrm{ppm}$ as an $8 \mathrm{~h}$ TWA. Forming these into groups gave low, medium, and high groups of $<20 \mathrm{ppm}$ ( $\mathrm{n}=$ $31), 20-40 \mathrm{ppm}(\mathrm{n}=47)$, and $>40 \mathrm{ppm}(\mathrm{n}=$ 26).

\section{Discussion}

DURATION OF EXPOSURE

Years of exposure used as a surrogate for dose represents the simplest approach to doseeffect and is used where exposure data are absent or very limited. It should be pointed out that in our study years of exposure were carefully assessed with reference to detailed job history questionnaires and information on plant history. Duration of exposure included only those years where actual exposure occurred and did not necessarily correlate with years employed with the company.

Duration of exposure is used as a surrogate for dose but does not distinguish the level of exposure. This means that highly exposed workers will be mixed with the usually larger number of workers exposed to low concentrations. For this reason and as exposure data were available for both sites, two alternative measures of dose, cumulative exposure, and intensity of exposure, were used.

DEVELOPMENT OF GROUPINGS BY CUMULATIVE EXPOSURE AND INTENSITY OF EXPOSURE

(1) Personal exposure history

There was some difficulty in attributing a job to a year from the duration and start date information given by the subjects as these sometimes conflicted. Interval calculation

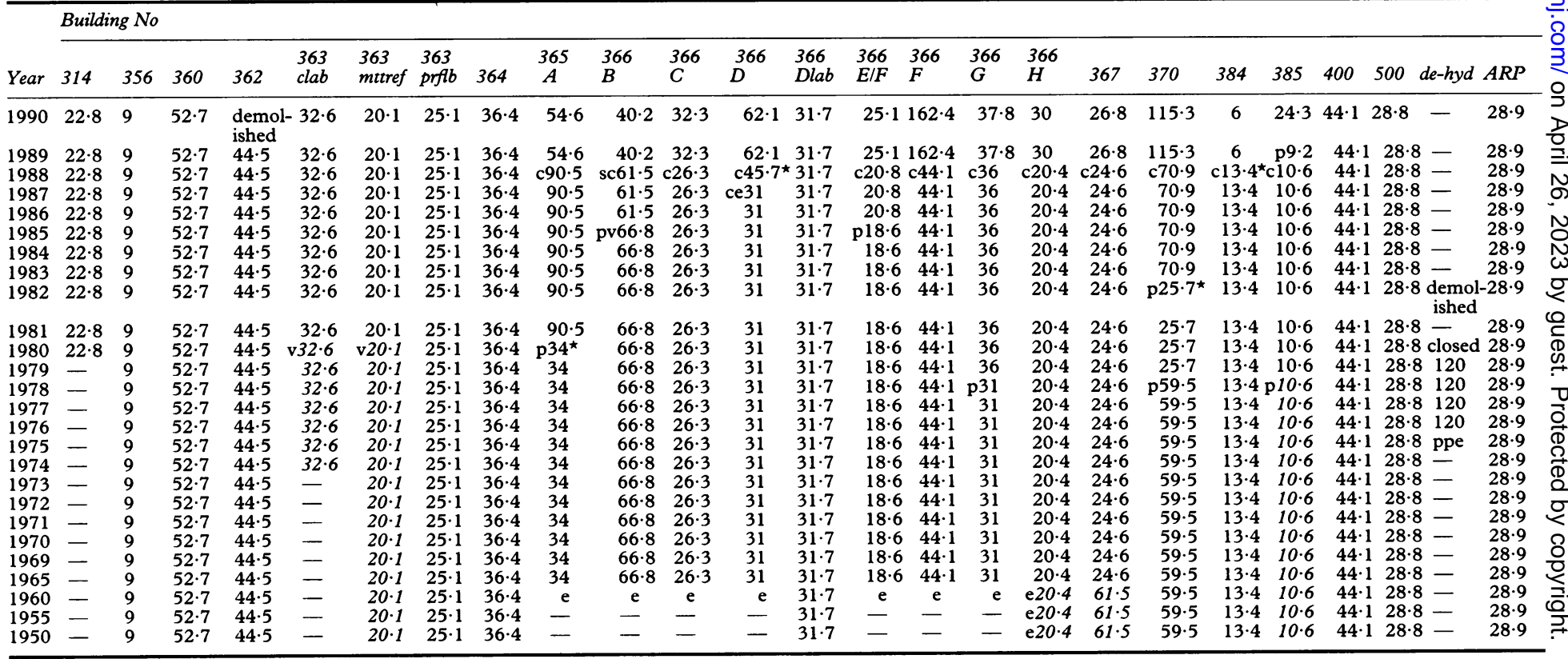

Footnotes as for table 3 . 
seems to be very difficult for many subjects and controls. Where there was uncertainty, the calendar year was used, rather than the number of years attributed by the subject to the job in question.

Subjects reported relatively few jobs outside the company that involved exposure to solvents for $>16 \mathrm{~h} /$ month. Previous exposure of paintmakers to lead, a potential confounder, was not considered important as earlier biological monitoring data carried out by the company indicated that very low levels of exposure occurred for this group of workers. ${ }^{10}$

For controls, significant exposure to solvents in previous jobs $(>16 \mathrm{~h} /$ month for $>3 \mathrm{y})$ would have caused exclusion from the study. Exposure to solvents from a hobby did not add to the years of exposure. No controls reported exposure to solvents from a hobby and there were only eight reports among subjects. The exposure from hobbies was not considered important as it would only marginally and with very poor precision, have increased the exposure estimates. Examples of hobbies reported are, 15 years as a maker of scale model aircraft, 20 years as an airfix modeller and doing car repairs, 23 years building and flying radio controlled aircraft, 20 years calligraphy.

\section{(2) Plant history}

Structuring the interviews used for data collection was necessary. In an interactive session, it was easy for information to be missed either because a question was omitted or because an answer was tangential. Extra data were gathered later during the history checking process. This iterative process was found to be useful.

The data that were not gathered consistently were those concerning overtime rates and relative production levels. This was not thought to have significantly affected exposure as there were no long periods of particularly high or low levels of production or long periods of layoff.

\section{(3) Choice of exposure index}

The situation is complex because there are two facilities and several different processes that use different solvents in different combinations. The mechanisms of any neuropsychological damage are unknown. All exposure to solvents should be considered but it is not obvious how to combine exposure to more than one solvent nor how to combine the different solvents. It is also not possible to decide whether dose is better expressed as the number of molecules (ppm) or as the mass of material $\left(\mathrm{mg} / \mathrm{m}^{3}\right)$. As the occupational hygiene data were already expressed in ppm and as other studies have also chosen to use $\mathrm{ppm}^{8}$ it was thought that, for pragmatic and comparative purposes, this measure would be more appropriate. Exposure was therefore defined as the cumulative TWA dose of total solvent measured in ppm.

The different solvents could have been combined by American Conference of Governmental Industrial Hygienists (ACGIH) mixtures formula but the use of current OELs as the denominators was not considered appropriate because the current United Kingdom OELs are not based on thresholds of neuropsychological damage or even on any effect on the central nervous system. It might have been preferable to weight the individual solvents in terms of their relative neurotoxicity. One way of doing this when several different solvents are present is to calculate exposure from effect specific limit values (ESLV) as the denominator in a mixtures formula calculation similar to that used by the ACGIH. The ESLV would have to be drawn from the scientific literature, mainly from animal studies as there is very limited human evidence. After this cumulative dose and intensity estimates would then be calculated. As the mechanism of any neurotoxic effect is unknown and there was no discernible difference between the results of the neuropsychological tests for subjects and controls, this somewhat speculative analysis was considered unnecessary.

The concept of latency was considered but not thought applicable to this study because the outcomes were measures that were not discrete but continuous variables and there was no information to justify the assumption that there was a time lapse between exposure and the development of clinical signs.

\section{(4) Construction of the exposure matrix}

The arithmetic mean of the data in a UEP was used. Occupational hygiene data generally have a log normal distribution and the geometric mean is the usual measure of mean exposure. It is felt however that the arithmetic mean is a better estimate of mean dose. ${ }^{18}$

As the data were limited there was a variability in the exposure estimates. Calculation of yearly means would often have been based on three or four readings, with the consequent variability in exposure estimate expected in occupational hygiene monitoring. ${ }^{18} \mathrm{~A}$ way of smoothing this variability was to take a mean of all the data that were collected under uniform production conditions. This is the UEP. Tables 3 and 4 show the periods for which there was a significant difference in the mean data for exposure between periods. Limitations in the number of data points within a period severely reduces the chance of showing significant differences between UEPs.

Variability of the data-The data on which the exposure estimates were based were taken over a period of time from the early 1970s. The sampling programme used a compliance monitoring strategy so that regular samples were taken in most buildings, but samples were taken more frequently in buildings where exposure had been found to be higher than the average for the whole facility. As the subjects were also divided on the basis of the building in which they worked, the compliance strategy should not bias the data, but results in a variation of the precision of the estimation of the mean exposure between areas, gave less precision in areas with lower levels of exposure. 
Measurements took place over varying time periods, and recently whole shift sampling has become more common. Samples from some shorter periods were also taken usually to investigate a particular procedure or task of concern. Inclusion of data taken over $>180$ min reduced the problem of short term task investigations weighting an average of the whole data, and giving an inaccurate (probably too high) mean exposure. There were more data available since 1985 . The less burdensome sampling equipment, more automated analysis, and the reduction in time spent on calibrating, servicing, and checking pumps, resulted in an increase in data accumulation.

Detection limits-It is normal in occupational hygiene carried out for epidemiological purposes to include some estimate of materials expected to be found at concentrations below the detection limit, because these could materially affect exposure estimation particularly for the low exposure group. The estimate would not normally be necessary for compliance monitoring, unless the detection limit is very high relative to the OEL. It has not been carried out on this data set for the following reasons. Firstly, the detection limits will vary with the sample volume and hence the calculations would have to be made separately for each sample. Secondly, it would be difficult to decide which sample should have which solvent or solvents included in such a calculation as these vary from task to task and over time. Thirdly, the change to the automated thermal desorber (ATD 50) system in 1982 resulted in much lower detection limits than were available previously. There were several different solvents present in different combinations in different areas. These are analysed automatically and not all solvents are expected to be found in all samples. Fourthly, the detection limit quoted by the analyst, 0.01 of the OEL, was higher in some cases than the exposures recorded. Hornung and Reed suggest that as a rule of thumb exposures below the detection limit should be assumed to be at half the detection limit for the purposes of estimating average exposure. ${ }^{19}$ If this had been carried out systematically, many of the non-detected values would have been assigned values greater than some of the detected values. This would clearly have been inappropriate. The non-detected or zero values reported from the surveys were therefore set at zero in the calculation of average exposures.

Retrospective exposure assessment in the absence of direct monitoring data-The assessor's level of expertise is an important factor in the accuracy of the exposure assessment carried out in the absence of adequate monitoring data. Kromhout et al have shown that hygienists are better at assessing level of exposure than plant supervisors or workers. ${ }^{20}$ Hawkins and Evans have carried out a study that showed that experienced industrial hygienists were competent at assessing levels of exposure for industrial processes with which they were reasonably familiar. ${ }^{21}$ Teschke et al, however, showed that senior workers familiar with the process were at least as good in their estimates as hygienists with experience in the industry sector, but not at the particular plant in question. ${ }^{22}$ Examination of some sampling data can improve the estimates but the precision of the estimation varies with the process. ${ }^{23}$ It was anticipated that the hygienists interviewed in this study would bring specialist knowledge of the plant as well as occupational hygiene experience to the estimates and that the estimates would be consequently of a high quality. These estimates were needed for relatively few areas and very few workers. Tables 3 and 4 show the periods in italics for which estimates were made. For plant A $15 \%$ of the total person-years and for plant B $19 \%$ of the total person-years were calculated from these estimates.

\section{(5) Allocation of personal exposure index}

Quantitative dose estimation based on personal monitoring data for each subject would ideally be considered a gold standard..$^{24}$ As personal monitoring had not been carried out on all individuals each day, group data were used to estimate an individual's mean exposure. The limited extent of the data, particularly for those people from the lower exposed areas and for the period before 1979, means that personal exposure assessment was of limited precision.

\section{(6) Group formation}

There was a wide range of exposure estimates showing that division by cumulative dose and intensity would result in a different distribution of subjects between categories than by duration alone. Subjects were divided by duration into four groups, and into three groups for cumulative dose and intensity for the main analysis. The division of subjects into three groups was partly for convenience of analysis but partly because there was a natural division into groups. Tables 5,6 , and 7 compare the individual worker's classification into high, medium, and low groups by the three methods. For this comparison the two

Table 5 Comparison of the classification of individuals' duration and cumulative dose

\begin{tabular}{lcccc}
\hline \multirow{2}{*}{$\begin{array}{l}\text { Duration of } \\
\text { exposure }(y)\end{array}$} & \multicolumn{4}{l}{ Cumulative exposure (ppm.y) } \\
\cline { 2 - 5 } & $<300$ & $300-600$ & $>600$ & Total \\
\hline$<11$ & 31 & 6 & 0 & 37 \\
$11-20$ & 10 & 21 & 8 & 39 \\
$>20$ & 1 & 10 & 17 & 28 \\
Total & 42 & 37 & 25 & 104 \\
\hline
\end{tabular}

Spearman's correlation coefficient $r=0.71, p<0.0001$.

Table 6 Comparison of the classification of individuals' duration and intensity of exposure

\begin{tabular}{lcccc}
\hline $\begin{array}{l}\text { Duration of } \\
\text { exposure }(y)\end{array}$ & \multicolumn{4}{c}{ Mean intensity of exposure $(p p m)$} \\
\cline { 2 - 5 } & $<20$ & $20-40$ & $>40$ & Total \\
\hline$<11$ & 15 & 12 & 10 & 37 \\
$11-20$ & 9 & 20 & 10 & 39 \\
$>20$ & 7 & 15 & 6 & 28 \\
Total & 31 & 47 & 26 & 104 \\
\hline
\end{tabular}

Spearman's correlation coefficient $r=0.07$, NS. 
Table 7 Comparison of the classification of individuals' cumulative dose and intensity

\begin{tabular}{lrccc}
\hline \multirow{2}{*}{$\begin{array}{l}\text { Cumulative } \\
\text { exposure (ppm.y) }\end{array}$} & \multicolumn{4}{c}{ Mean intensity of exposure (ppm) } \\
\cline { 2 - 5 } & $<20$ & $20-40$ & $>40$ & Total \\
\hline$<300$ & 24 & 12 & 6 & 47 \\
$300-600$ & 7 & 24 & 6 & 42 \\
$>600$ & 0 & 11 & 14 & 24 \\
Total & 31 & 47 & 26 & 104 \\
\hline
\end{tabular}

Spearman's correlation coefficient $r=0.51, P>0.0001$

groups of longest serving employees were combined to give three groups by duration of about equal sizes.

Cumulative exposure shows significant correlation with both duration (Spearman's correlation coefficient $r=0.71, \mathrm{p}<0.0001)$ and intensity $(r=0.51, \mathrm{p}<0.0001)$, as might be expected from the fact that it is the product of the two. Intensity and duration of exposure are not significantly associated $(r=0.07, \mathrm{NS})$. This suggests that the average exposure experience amongst the longer serving employees is similar to the shorter serving employees.

Assuming that the cumulative dose is a better estimate of exposure than duration alone, the categorisation by duration shows that one third of subjects are misclassified by one category (only one subject was misclassified by two categories). The categorisation by intensity shows that over $60 \%$ of subjects are misclassified by at least one category compared with duration. Checkoway has shown that these degrees of misclassification can have a significant effect on the outcome of a study depending on the rarity of the effect under investigation. ${ }^{24}$

\section{RISK ASSESSMENT}

Because the data presented in the exposure matrices are expressed in total ppm of solvent in air, it is difficult to judge the exposures against current limits for risk assessment purposes. Table 1 shows the exposure data applicable to most of the subjects. For the sake of uniformity, the measured concentrations were divided by the 1992 United Kingdom OELs listed (table 2). This was necessary because for instance, the exposure limit for toluene was recently reduced and the formulas calculated for 1980 would not have reflected this new value. In some cases, such as for glycol ethers, the denominator used by the company for calculation of compliance, changed in advance of the official limit. These changes are not clearly recorded in the sampling records and without recalculation, the data are not easily comparable between years. Analysis of the 1980 and 1985-1990 data with the mixtures formula shows that solvent levels are typically well below the compliance levels. A few areas show excursions above the compliance standards, in one area $11 \%$ of readings were above unity. This group of paintmakers would seem to be routinely exposed to low levels of solvents.

\section{Conclusions}

The first objective of the exposure assessment was to ensure that exposure to solvents had occurred for subjects and had not occurred for controls. A careful examination of each individual's job history is needed to properly allocate them to an exposed group or to eliminate them as unsuitable controls because of previous exposure. A high proportion of paintmakers who were interviewed had not had significant exposure to solvents. The exposure had either been too short or they had worked in jobs that did not result in significant exposure to solvents. For most of the subjects, calculating years of employment based on current job allocation would not have resulted in a satisfactory estimate of years of exposure.

Exposure data were available for several years before the investigation. Although data were not available for all areas over the whole period of interest and had been collected for compliance purposes it nevertheless allowed a much more accurate picture of each individual's long term exposure to be developed than had been the case in many earlier studies.

Preparation of a thorough plant history before the analysis of sampling data allowed the preparation of a time specific exposure matrix, which enabled a detailed characterisation of an individual's exposure history to be carried out.

Classification of exposure by duration alone is a reasonable predictor of classification by cumulative dose estimate but still results in misclassification of one third of subjects. It is a poor surrogate for intensity of exposure. The use of monitoring data should thus have reduced the misclassification of subjects, this was the second objective of the exposure assessment.

It should be recalled, however, that the overall exposure to solvents for this group is only exceptionally over the exposure limit calculated from the mixture's formula. Paintmakers are exposed routinely to only low levels of solvents.

This project was part of a neuropsychological assessment of the effect of organic solvents on paintmakers and was funded by ICI Paints Limited. We gratefully acknowledge the help provided by Mr R Clements, Mr G Thurlow, Mr G O'Keeffe, and Mr D Jones who collected and helped to interpret the occupational hygiene monitoring data. Thanks are also due to occupacion also due to Mr Cunningham-Hill, Ms J Walker, Ms N Shard, Ms Edwards, Dr S Jones, and the team who helped us with the particularly thank the workers who participated in the study.

1 Axelson $\mathrm{O}$, Hane M, Hogstedt C. A case referent study of neuropsychiatric disorders among workers exposed to solvents. Scand $\mathcal{F}$ Work Environ Health, 1976;2:14-20.

2 Olsen J, Sabroe S. A case referent study of neuropsychiatric disorders among workers exposed to solvents in the Danish wood and furniture industry. Scand $\mathcal{F}$ Soc $\mathrm{Med}$ 1980;16:44-9.

3 Lindstrom K, Riihiamaki H, Hanninen H. Occupationa solvent exposure and neuropsychiatric disorder. Scand $\mathcal{F}$ Work Environ Health 1984;10:321-3.

4 Elofssen SA, Gamberale F, Hindmarsh I, Iregren A Isaksson A, Johnsson I, et al. Exposure to organic solvents. A cross-sectional epidemiological investigation vents. A crally exposed and industrial spray pain on occupationally exposed car and industrial spray painter with special reference to the nervo

5 Cherry N, Hutchins H, Pace T, Waldron HA Neurobehavioural effects of repeated occupational exposure to toluene and paint solvents. $B r^{\prime} f$ Ind Med sure to toluene
$1985 ; 42: 291-300$ 
6 Maizlish NA, Langolf GD, Whitehead LW, Fine LJ, Albers JW, Goldberg J, Smith P. Behavioural evaluation of workers exposed to mixtures of organic solvents. $\mathrm{Br} F$ Ind Med 1985;42:579-90.

7 Maizlish NA, Fine LJ, Albers JW, Whitehead L, Langolf GD. A neurological evaluation of workers exposed to mixtures of organic solvents. Br f Ind Med 1987;44:14-25.

8 Ford DP, Schwartz BS, Powell S, Nelson T, Keller L, Sides S. et al. A quantitative approach to the characterization of cumulative and average solvent exposure in paint manufacturing plants. Am Ind Hyg Assoc f 1991;52:226-34.

9 Triebig G, Claus D, Csuzda I, Druschky KF, Holler P, Kinzel W, et al. Cross sectional epidemiological study on neurotoxicity of solvents in paints and lacquers. Int Arch Occup Environ Health 1988;60:233-41.

10 Spurgeon A, Glass DC, Calvert IA, Cunningham Hill MC, Harrington JM. Neurobehavioural performance and mental health in paint manufacturing workers exposed to low levels of solvents. Occup Environ Med 1994;51:626-30.

11 Checkoway H, Savitz DA, Heyer N. Assessing the effects of nondifferential misclassification of exposures in occupational studies. Appl Occup Environ Hyg

12 Copeland KT, Checkoway H, McMichael AJ, Holbrook $\mathrm{RH}$. Bias due to misclassification in the estimation of relative risk. Am $\mathcal{F}$ Epidemiol 1977;105:488-95.

13 Dement JM, Harris RL, Symons MJ, Shy CM. Exposures and mortality among chrysotile asbestos workers; pt 1 exposure estimates. Am F Ind Med 1983;4:399-419.

14 Spurgeon A, Gray CN, Sims J, Calvert I, Levy LS, Harvey PG, Harrington JM. Neurobehavioural effects of long- term occupational exposure to organic solvents. Two comparable studies. Am f Ind Med 1992;22:325-35.

15 Statistical packages for the Social Sciences. SPSS/PC for the IBM PC/XT/AT and PS/2. Chicago SPSS, 1986

16 American Conference of Governmental Industrial Hygienists. 1992-1993 Threshold limit values for chemical substances and physical agents and biological exposure substances and physical agents and

17 Health and Safety Executive. Guidance note EH4O occupational exposure limits 1992. London: HMSO, 1992.

18 Rappaport SM (1991) Assessment of long term exposures to toxic substances in air. Ann Occup Hyg 1991;35:61-121.

9 Hornung RW, Reed LD. Estimation of average concentration in the presence of nondetectable values. Applied Occupational Environmental Hygiene 1990;5:46-51.

20 Kromhout H, Oostendorp Y, Heederick D, Boleij JSM. Agreement between qualitative exposure estimates and quantitative exposure measurements. $A m$ F Ind Med 1987;12:551-62.

21 Hawkins NC, Evans JS. Subjective estimation of toluene exposures: a calibration study of industrial hygienists. Applied Industrial Hygiene 1989;4:61-8.

22 Teschke K, Hertzman C, Dimich-Ward H, Ostry A, Blair J, Hershler R. A comparison of exposure estimates by Hershler R. A comparison of exposure estimates by worker raters and industrial hyg

23 Post W, Kromhout H, Heederick D, Noy D, Duijzentkunst RS. Semiquantitative estimates of exposure to methylene chloride and styrene: the influence of quantitative exposure data. Applied Occupational and Environmental Hygiene 1991;6:197-204.

24 Chekoway $\mathrm{H}$. Methods of treatment of exposure data in occupational epidemiology. Med Lav 1986;77:48-73.

\section{Instructions to authors}

Three copies of all submissions should be sent to: The Editor, Occupational and Environmental Medicine, BMJ Publishing Group, BMA House, Tavistock Square, London WC1H 9JR, UK. All authors should sign the covering letter as evidence of consent to publication. Papers reporting results of studies on human subjects must be accompanied by a statement that the subjects gave written, informed consent and by evidence of approval from the appropriate ethics committee. These papers should conform to the principles outlined in the Declaration of Helsinki (BMF 1964;ii:177).

If requested, authors shall produce the data on which the manuscript is based, for examination by the Editor.

Authors are asked to submit with their manuscript the names and addresses of three people who they consider would be suitable independent reviewers. They will not necessarily be approached to review the paper. 